\title{
Optimal Coordination of Directional Overcurrent Relays using Particle Swarm Optimization Technique
}

\author{
A.Rathinam \\ Asst.Prof
}

\author{
D.Sattianadan \\ Asst. Prof
}

\author{
K.Vijayakumar \\ Asst.Prof
}

\author{
S.R.M UNIVERSITY, Chennai, Tamilnadu, INDIA
}

\begin{abstract}
-
The main function of the protective devices in the power system is to detect and remove the selected faulty parts as fast as possible. Directional over current relays are commonly used for the protection of interconnected sub transmission systems, distribution systems, or as a secondary protection of transmission systems. For the systems having more than one source connected, that is meshed or looped networks, directional over current relays become the suitable choice for better selectivity, since directional relays operate only when the fault current flows in the specific tripping direction desired. The most vital task when installing directional relays on the system is selecting their suitable current and time settings such that their fundamental protective functions are met under the requirements of sensitivity, selectivity, reliability and speed. The problem of setting Directional Over Current Relay(DOCR) is a highly constrained optimization problem that has been solved as a linear programming problem. The calculation of the time dial setting (TDS) and pick up current (IP) setting of the relays is the core of the coordination. This paper calculates the TDS by choosing one of the available pick up current settings as the predetermined value. The simplex two phase method is used to determine the optional TDS of the relays. Improvement in the solution is brought by using the particle swarm optimization technique to the co-ordination problem for reaching the global optimum value with less computational time. Sample 3 bus and 8 bus systems are utilized for comparing the results obtained by PSO with that of the simplex method. The optimization method used in the recent times minimizes the operating time of the relays much, when compared to the other methods. This method also enhances quicker solution of coordination process.
\end{abstract}

Index terms: Interconnected networks, Directional overcurrent relaying, optimal coordination, linear programming

\section{INTRODUCTION}

In an interconnected power system, abnormal conditions (faults, overload, over voltage, etc.) can frequently occur. Due to this, interruption of the supply and damage of equipments connected to the power system may occur. During these situations, the faulted components must be readily identified and isolated in order to guarantee the energy supply to the largest number of consumers as possible and to maintain the system stability. Therefore a reliable protective system is required. So, to ensure reliability, a backup protective system should be provided in the case of failure of main or primary protective device (relay failure or breaker failure). This backup protection should act as a backup either in the same station or in the neighboring lines with time delay according to the selectivity requirement. This time delay ensures reliability, so that the backup system doesn't come into action unless the primary system fails. The determination of the time delays of all backup relays is known as coordination of the protection system. This time delay is known as Coordination Time Interval (CTI) $[1,2,3]$.

For the past few decades, directional over current relays are commonly used as a primary protection in distribution and transmission systems and as a secondary protection or employment of distance relays in transmission systems. A great deal of effort has been devoted to the automation of the solution of the coordination problem of directional overcurrent relays in power systems. Several approaches have been used for the setting of directional over current relays like trial and error method. topological analysis method and optimization method $[7,8,9,10]$.

\section{OptIMIZATION (PSO)}

Particle Swarm Optimization is a stochastic, population-based computer algorithm for problem solving. It is a kind of swarm intelligence that is based on social-psychological principles and provides insights into social behavior, as well as contributing to Engineering applications. The particle swarm optimization algorithm was first described in 1995 by James Kennedy and Russell C. Eberhart. PSO has been recently adopted due to its superiority to other Evolutionary Algorithms (EA) regarding its memory, and computational time requirements as it relies on very simple mathematical operations, also it requires very few lines of computer code to implement. Numerous optimization algorithms have been developed to solve these problems, with varying degrees of success. The PSO is a relatively new technique that has been empirically shown to perform well on many of these optimization problems $[11,12]$.

The underlying motivation for the development of PSO algorithm was social behavior of animals such as bird flocking, fish schooling, animal herding and swarming theory. The PSO algorithm possesses some attractive properties such as memory (i.e. every particle remembers its best solution), the initial population is maintained throughout (i.e. it is not necessary to apply operators such as recombination, selection, etc. to the population) and constructive cooperation between particles. 
In this paper, the problem of coordinating directional over current relays in power systems is stated and solved in the framework of optimization theory. The proposed approach determines the "optimal" solution to this coordination problem in a cost effective and efficient way, by stating the problem as a parameter optimization problem, and solving it using efficient optimization techniques. Here the optimization of Time Dial Setting and minimized function got from Linear programming with Large-Scale: Interior Point in Matlab has been done by Particle swarm Optimization technique coded in C\#. It is pertinent to mention here that the Optimization methodology presented in this paper can also be applied to the problem of optimal coordination of protective relays other than directional over current relays (e.g. distance relays [9]). The optimization approach and its particularization to the case of directional over current relays are presented below

\section{DOCR OPTIMAL COORDINATION PROBLEM}

DOCR coordination problem is a parametric optimization problem, where different constraints have to be considered in solving the objective function. Here the objective function to be minimized is the sum of the operating times of the relays connected to the system, subject to the following constraints.

\section{A. Relay Characteristics:}

A typical inverse time directional overcurrent relay has two units, an instantaneous unit(time independent) and an inverse overcurrent unit (time dependent). The time dependent unit has two values to be set, the pickup current (Ip) and the time dial setting (TDS). The pickup value is the minimum value of current for which the relay operates. The time dial setting defines the operating time $(\mathrm{T})$ of the relay for each current value. The characteristics of the OCR are given as a curve of $\mathrm{T}$ versus $\mathrm{M}$, where, i.e.

$$
M=I / I_{P}
$$

Where $I$ is the relay current (overload/fault current). M is a multiple of the pickup current and $\mathrm{I}_{\mathrm{P}}$ is the pickup current.

Here the overcurrent relay is conformed to the following IEC characteristic $[6,10]$. The following formula is used to approximately represent the inverse overcurrent relay characteristics.

$$
\mathrm{T}=\mathrm{k}_{1} \cdot \mathrm{TDS} /\left(\mathrm{M}^{\mathrm{k} 2}-1\right)
$$

Where $\mathrm{k}_{1}$ and $\mathrm{k}_{2}$ are constants that depend on the relay characteristics.

The relation between the operating time $(\mathrm{T})$ of the time overcurrent unit and the multiple of pickup current (M), is nonlinear. The multiple of pickup current of the relays can be predetermined and so for a fixed $\mathrm{M}$, the above equation can be rewritten as

$$
\begin{aligned}
& T=a \cdot T D S \\
& \text { Where } a=\frac{K_{1}}{M^{k_{2}}-1}
\end{aligned}
$$

\section{B. Relay Settings:}

The calculation of the two settings, TDS and $I p$, is the essence of the directional Overcurrent relay coordination study. It is very important to mention that in general, directional overcurrent relays allow for continuous time dial settings but discrete (rather than continuous) pickup current settings.

Therefore this constraint can be formulated as:

$$
\begin{aligned}
& T D S_{i_{\text {min }}} \leq T D S_{i} \leq T D S_{i_{\max }} \\
& \mathrm{I}_{\text {pi min }} \leq \mathrm{I}_{\text {pi }} \leq \mathrm{I}_{\text {pi max }}
\end{aligned}
$$

\section{Coordination Formulation:}

In any power system, a primary protection has its own backup one for guaranteeing a dependable power system. The two protective systems (primary and back-up) should be coordinated together. Coordination time interval (CTI) is the criteria to be considered for coordination. It's a predefined coordination time interval and it depends on the type of relays. For electromagnetic relays, CTI is of the order of 0.3 to $0.4 \mathrm{~s}$, while for a microprocessor based relay, it is of the order of 0.1 to $0.2 \mathrm{~s}$.

To ensure reliability of the protective system, the back-up scheme shouldn't come into action unless the primary (main) fails to take the appropriate action. Only when CTI is exceeded, backup relay should come into action.

This case is expressed as

$$
T_{\text {backup }}-T_{\text {primary }} \geq C T I
$$

Where $T_{\text {backup }}$ is the operating time of the backup relay. $T_{\text {primary }}$ is the operating time of the primary relay.

After considering all these criteria, this problem can be formulated mathematically as

$$
\min \sum_{i=1}^{n} a_{i} \cdot T D S_{i}
$$

Where $i=1$ to $n, n$ represents the number of relays.

\section{ALOGRITHAM OF PSO}

PSO1: Initialize positions and associated velocity of all particles (potential solutions) in the population randomly in the $\mathrm{D}$ dimension space.

PS02: Evaluate the fitness value of all particles.

PS03: Compare the PBEST of every particle with its current fitness value. If the current fitness value is better, then assign the current fitness value to PBEST.

PS04: Determine the current best fitness value in the whole population. If the current best fitness value is better than the $G B E S T$, then assign the current best fitness value to GBEST .

PS05: Change velocities using t8he following equation:

$\mathrm{V}(\mathrm{t}+1) \mathrm{id}=\mathrm{w} \times \mathrm{vi}(\mathrm{t})+\mathrm{c} 1 \times \operatorname{rand}() \times($ pbestid $-\mathrm{S}(\mathrm{t}) \mathrm{id})+\mathrm{c} 2 \times$ Rand ()$\times($ gbestd $-\mathrm{S}(\mathrm{t}) \mathrm{id})$

Where

$i=1,2---\mathrm{n} ; \mathrm{d}=1,2---\mathrm{m}$.

' $\mathrm{n}$ ' is the population size,

' $m$ ' is the number of units and

the ' $w$ ' value is set using:

$\mathrm{w}=\mathrm{wmax}-((\mathrm{wmax}-\mathrm{wmin}) /$ itermax $) \times$ iter 
where, $\operatorname{wmax}=0.9 ;$ wmin $=0.4$.

$\mathrm{c} 1$ and $\mathrm{c} 2$ are two positive constants

rand()are random function in the range $[0,1]$.

Using the above equation, a certain velocity, which gradually gets close to pbest and gbest, can be calculated. The current position can be modified by the following equation:

$\mathrm{S}(\mathrm{t}+1) \mathrm{id}=\mathrm{S}(\mathrm{t}) \mathrm{id}+\mathrm{V}(\mathrm{t}+1)$ id

PS06: Move each particle to $\mathrm{S}(\mathrm{t}) \mathrm{id}+\mathrm{V}(\mathrm{t}+1)$ id

PS07: Repeat steps PSO2-PSO6 until a stop criterion is satisfied OR a pre specified number of iterations is completed

\section{A. Three Bus System:}

The system under study is a 3 bus system as shown in Fig.1. Identical directional overcurrent relays with inverse characteristics have been used in these examples, so that $\mathrm{k} 1=0.14, \mathrm{k} 2=0.02$.

\section{B. Eight Bus System:}

In this section the proposed method will be illustrated using the 8-bus, 9-branch network, taken from and shown in figure 3.

This figure also specifies the location of directional overcurrent relays. The above algorithms can also be implemented using the Microcontrollers using the relevant hardware circuits.

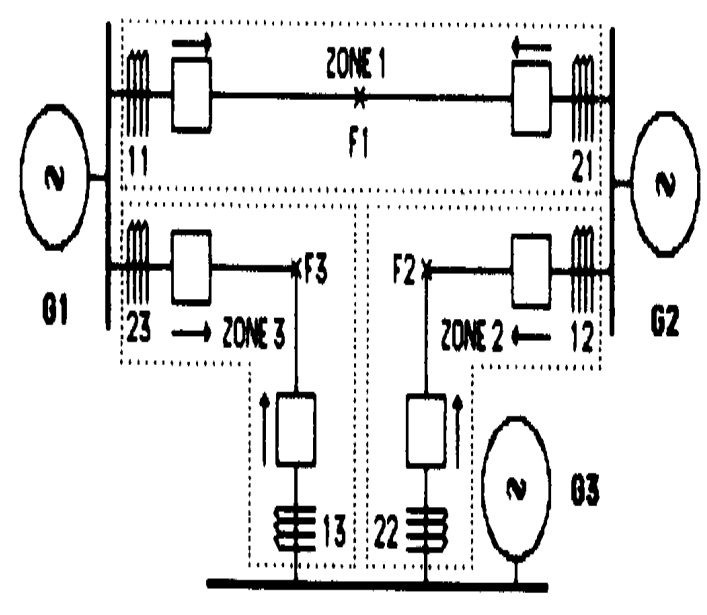

Fig 1. Three Bus System

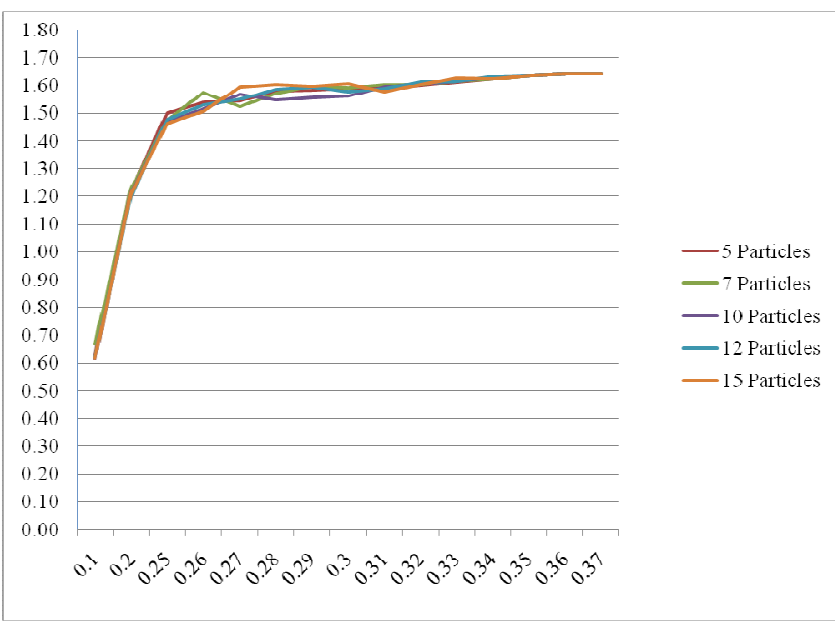

Fig 2. Effect of particle on convergence

TABLE I

COMPARISION OF RELAY OPERATING TIME BY LPP AND PSO TECHNIQUE FOR 3 BUS SYSTEMS
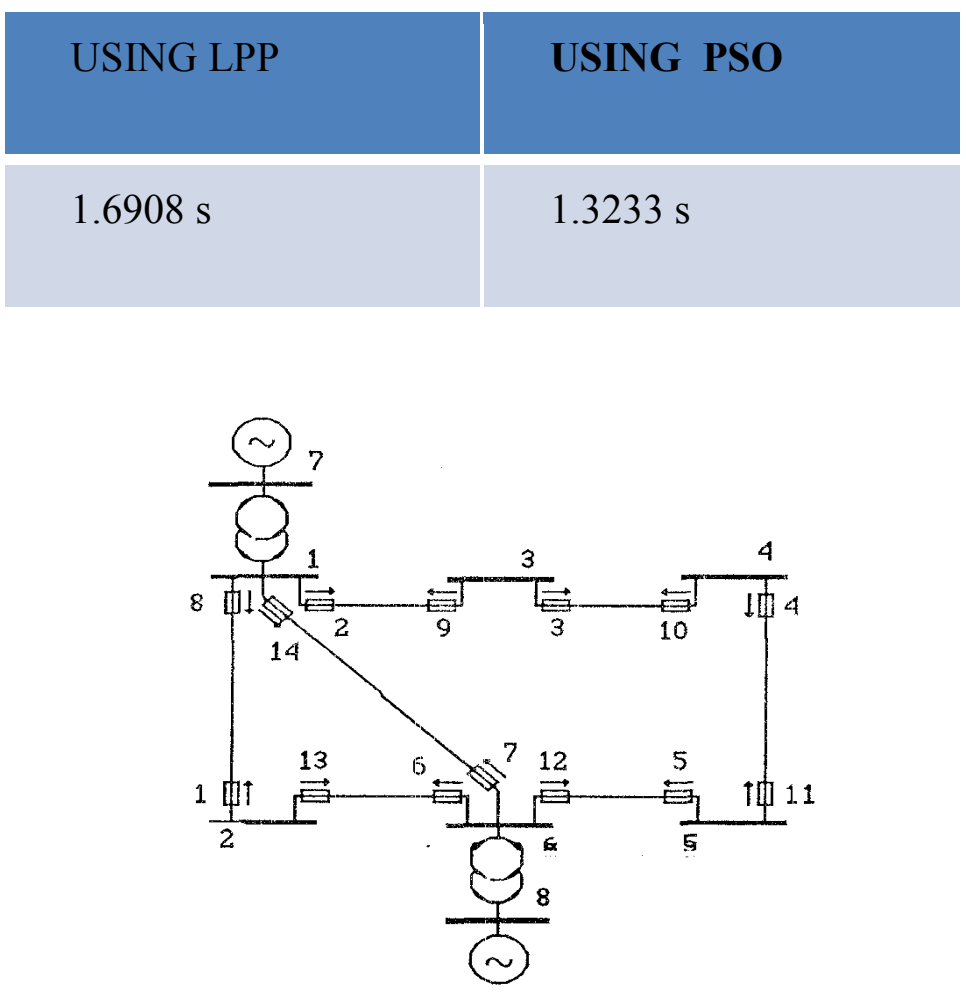

Fig 3. Eight Bus System. 
TABLE 2

COMPARISION OF RELAY OPERATING TIME BY LPP AND PSO TECHNIQUE FOR 8BUS SYSTEMS
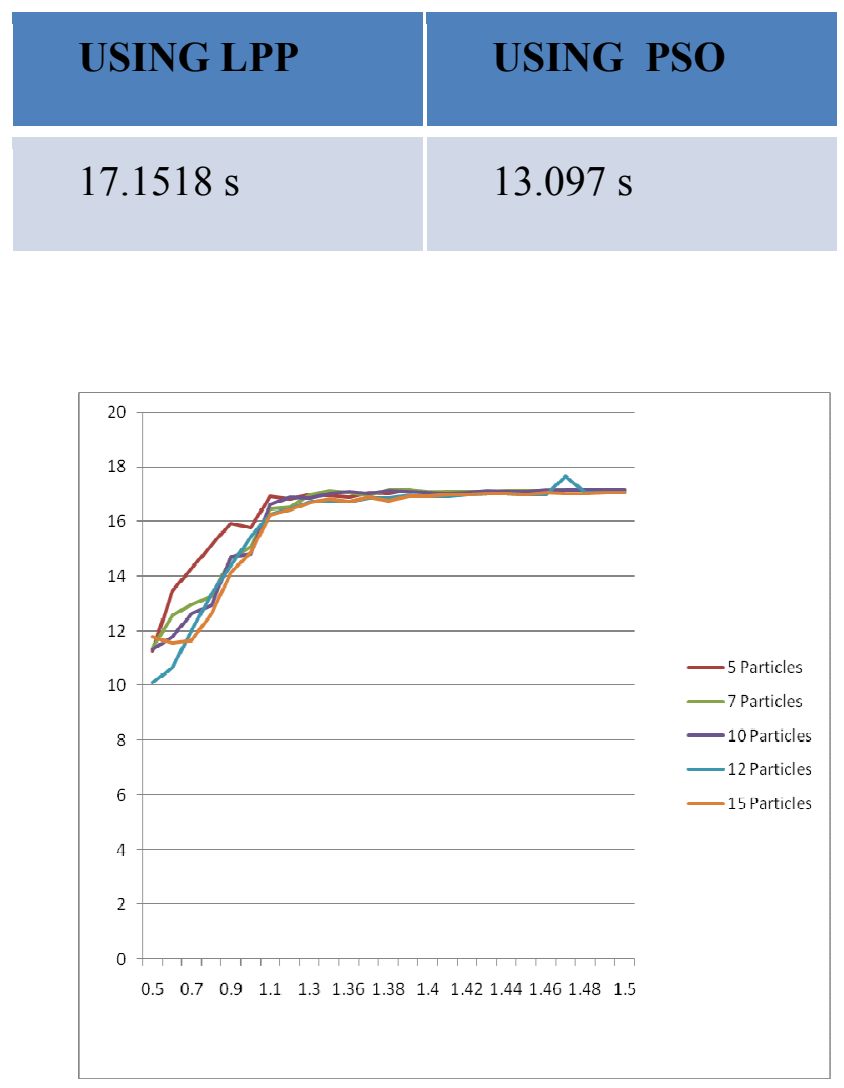

Fig 4. Effect of particle on convergence

In the above figures 3 and 4 , the convergence characteristics of PSO for the varied number of particles and the learning index - a constant which is used in MPSO algorithm is given. It is provided to prove the convergence ability of the MPSO.

\section{CONCLUSION}

In this paper, an optimization methodology is presented to solve the problem of coordinating directional overcurrent relays in an interconnected power system. The operating time of the relay was determined using MATLAB and is found to be $1.6908 \mathrm{~s}$ for Three bus system and 17.1518s for Eight bus system. This value is further optimized using Modified Particle Swarm Optimization technique in C\#. A Linear Programming problem formulation was presented in this project for the optimal coordination of Directional Over Current Relays. It is found that MPSO requires only five particles for the optimization of the objective function. Therefore the proposed algorithm was used to obtain the optimal setting of the operation time of the directional over current relays in the two case study system, a 3-bus system and an 8-bus system. The operating time values are found to be $1.3233 \mathrm{~s}$ for three bus system and 13.097s for eight bus System. On studying these two cases and comparing the results with those obtained from
MATLAB, it is seen that the objective function of the DOCR relay is minimized.

The optimization of the coordination of Directional over current relays can be further improved by considering or formulating new coordination constraints. Further, by improving the existing features of MPSO like updating PSO technique, the optimization of relay coordination can be improved.

\section{REFERENCES}

[1] P.M. Anderson, Power system Protection. Newyork: McGraw-Hill, 1999.

[2] Warrington, ARC, The Protective Relays. Theory and Practice, John Wiley 8 Sons, New York, 1969.

[3] Westinghouse Electric Corp., Applied Protective Relaying, Westinghouse Electric Corp., Newark, NJ. 1979.

[4] General Electric Co. Measurements, Protective Relays Application Guide, GEC, United Kingdom, 1975.

[5] A. J. Urdenta, et al. "Optimal Coordination of Directional Over current Relays in Interconnected Power Systems", IEEE Trans. on Power Delivery, Vol. 3, July 1988, pp. 903-911.

[6] Quanming Yue, Feipeng Lu, Weiyong Yu, and Jie Wang "A Novel Algorithm to Determine Minimum Break Point Set for Optimum Cooperation of Directional Protection Relays in Multiloop Networks" IEEE Transactions on power delivery, Vol. 21, pp.1114-1119,July2006

[7] N. A. Laway, H. O. Gubta, "A Method for Coordination of Over current Relays in an Interconnected Power Systems", IE Journal, Vol. 74,August1993,pp.59-65..

[8] Urdaneta, AJ."Minimax Optimization for Power System Control: A Multiple Objective Approach," PhD Dissertation, Case Western Reserve University,

[9] IEC Standard, Single Input Energizing Quantity Measuring Relays with Dependent Specified Time, Publication No. 255-4, 1976.

[10] C.W.So, K.K.Li "Application of genetic algorithm for overcurrent relay coordination", IEE $6^{\text {th }}$ international conference on development in power system protection, Nottingham, UK, March 1997, pp 66-69

[11] B.Chattopadhyay, M.S.Sachedev and T.S.Sidhu,"An On Line relay Coordination Algorithm for Adaptive protection using Linear Programming Techniuqe", IEEE Transaction on power Delivery, Vol. 11, No.1, January 1996, pp.165-173

[12] J.Kennedy and R. Eberhart, "Particle swarm optimization" in Proc. IEEE Neural Networks Conf.Piscataway, NJ, 1995, pp 1942-1948

[13] Y.Shi and R.Eberhart," A modified particle swarm optimizer" in Proc IEEE Int.Conf, on Evolutionary Computation, 1998, pp 69-73 


\section{BIOGRAPHIES:}

A. Rathinam currently holds the position of Assistant Professor of the EEE Department at the SRM University, Chennai, India. He received his Bachelor of Engineering degree from the Faculty of Engineering and Technology, Annamalai University, India and Master of Engineering from the same university in the year 1996 in Power Systems Engineering. He is currently pursing his PhD degree in SRM University in the area of Multidimensional Digital Signal Processing. He has 4 International Journals and 23 papers in International Conferences which includes conferences Sponsored by both IEEE and IET. He has been awarded Best teacher award in the department for the academic year 2005. His area of research interests includes Computational Intelligence applications in Power systems and Analog integrated circuits, Digital Signal Processing, Electrical Machines, Microprocessors and Microcontrollers.

D. Sattianadan received the Bachelor of Engineering in Electrical and Electronics Engineering from Madras University in the year 2000 and Master of Engineering in Power systems from Anna University in the year 2005. He is currently working as Assistant professor in the Department of Electrical and Electronics Engineering, SRM University, Chennai, India. His area of interest includes Power System Operation and Control, FACTS and Power System Protection. Also, he is working towards his doctoral degree in the area of Distributed Generations in Distributed Systems.
K. Vijayakumar currently holds the position of Assistant Professor of the EEE Department at the SRM University, Chennai, India. He received his Bachelor of Engineering degree from the Faculty of Engineering and Technology, Annamalai University, India, Master of Engineering from the same university in the year 1996 in Power Systems Engineering. He is currently pursing his Ph.D degree in Anna University in the area of Deregulation systems.He has published 4 international journals and 15 international Conferences. His area of research interests includes Computational Intelligence applications in Power Systems, FACTS and Power System Operation and Control. He has been awarded Best teacher award in the department for the academic year $2004 \& 2006$. 